\title{
Metabolic Approach to the Enhancement of Antitumor Effect of Chemotherapy: a Key Role of Acetyl-L-Carnitine
}

\author{
Claudio Pisano ${ }^{1}$, Loredana Vesci ${ }^{1}$, Ferdinando Maria Milazzo ${ }^{1}$, Mario Berardino Guglielmi ${ }^{1}$, Rosanna Foderà ${ }^{1}$, \\ Marcella Barbarino ${ }^{1}$, Maurizio D'Incalci ${ }^{2}$, Massimo Zucchetti ${ }^{2}$, Giovanna Petrangolini ${ }^{3}$, Monica Tortoreto ${ }^{3}$, Paola Perego ${ }^{3}$, \\ Valentina Zuco ${ }^{3}$, Augusto Orlandi ${ }^{4}$, Daniela Passeri ${ }^{4}$, Paolo Carminati ${ }^{1}$, Claudio Cavazza ${ }^{1}$, and Franco Zunino ${ }^{3}$
}

\section{Abstract}

Purpose: Acetyl-L-carnitine (ALC) plays a relevant role in energy metabolism and stress response because of its function in the complex metabolic system regulating the acetyl-CoA levels that provide a source of acetyl groups for metabolic and acetylation-regulated processes. Because acetylation may influence p53 activity/stability and, therefore, the response to platinum compounds, this study was designed to investigate the effect of ALC in combination with platinum compounds.

Experimental Design: The antiproliferative and antitumor activity studies were done in a panel of human tumor cell lines with functional or defective p53. The antimetastatic drug efficacy was investigated in the s.c. growing $\mathrm{H} 460 / \mathrm{M}$ tumor subline, which is able to generate lung metastases.

Results: ALC enhanced the sensitivity to cisplatin of tumor cells with functional p53. The sensitization by ALC was reflected in an improved in vivo antitumor efficacy of the combination over cisplatin alone in wild-type p53 lung tumors. ALC did not increase the cisplatin efficacy in the p53-mutant SW620 tumor. ALC exhibited a significant antimetastatic activity, and this effect was better exploited in combination with the histone deacetylase inhibitor, ST3595. The in vivo ALC/cisplatin combination caused the activation of p53, associated with protein acetylation and induction of target genes.

Conclusions: ALC was effective in enhancing the antitumor potential of platinum compounds in wildtype p53 tumors. ALC, alone and in combination with a histone deacetylase inhibitor, exhibited an outstanding antimetastatic activity. Both effects, likely mediated by protein acetylation, may have implications for platinum-based therapy and combinations with histone deacetylase inhibitors. Clin Cancer Res; 16(15); 3944-53. $\odot 2010$ AACR.

The carnitine system, consisting of L-carnitine, carnitine esters, specific enzymes, and membrane transporters, plays a central role in energy metabolism (1-4). Because the ester of carnitine, acetyl-L-carnitine (ALC), has been implicated as a modulator of stress response, manipulation of this system may represent a promising approach for protection against stress-related diseases, including neurodegenerative disorders and chemotherapy-induced neurotoxicity $(4,5)$.

\footnotetext{
Authors' Affiliations: ${ }^{1}$ Oncology Area Research \& Development, SigmaTau, Pomezia, Italy; 2Department of Oncology, Istituto di Ricerche Farmacologiche "Mario Negri" and 3Fondazione Istituto Di Ricovero e Cura a Carattere Scientifico Istituto Nazionale Tumori, Milan, Italy; and ${ }^{4}$ Department of Biopathology and Image Diagnostics, Tor Vergata University of Rome, Italy
}

Note: Supplementary data for this article are available at Clinical Cancer Research Online (http://clincancerres.aacrjournals.org/).

Corresponding Author: Claudio Pisano, Oncology Area-R\&D, Sigma-Tau Industrie Farmaceutiche Riunite S.p.A., Via Pontina, Km. 30.4, 00040 Pomezia (Rome), Italy. Phone: 39-06-91-39-37-60; Fax: 011-39-06-91-3939-88; E-mail: claudio.pisano@sigma-tau.it.

doi: 10.1158/1078-0432.CCR-10-0964

(C)2010 American Association for Cancer Research.
In particular, ALC is implicated in the regulation of the acetyl-CoA level, resulting in an increased ratio of acetyl$\mathrm{CoA}$ to $\mathrm{CoA}(3,4)$. This function, mediated by carnitine acetyl transferase, is relevant for mitochondrial energy production and other biosynthetic processes (3). At the nuclear level, ALC provides a source of acetyl groups for nuclear protein acetylation by histone acetyl-transferases (6). Acetylation of the transcription factor p53 by histone acetyl transferase p300/CBP has been reported to enhance its transcriptional activity (7). Because p53 is also a substrate for histone deacetylases (HDAC; ref. 8), it is conceivable that ALC may have a cooperative effect in combination with agents able to modulate p53 protein acetylation.

P53 is a critical determinant of cellular response to antitumor DNA-damaging agents, in particular to platinum compounds $(9,10)$. Indeed, the functionality of the p53-activated pathway has been positively correlated with the cytotoxicity of platinum compounds $(11,12)$. Based on this rationale, the present study was designed to investigate the effects of ALC in combination with platinum compounds. The results obtained in three human nonsmall cell lung cancer (NSCLC) models characterized by wild-type $p 53$ gene status indicated the ability of ALC to enhance the antitumor efficacy of cisplatin. These results 


\section{Translational Relevance}

Extended first-line platinum-based chemotherapy in non-small cell lung cancer (NSCLC) with combination regimens for more than six to seven cycles is not recommended because of cumulative toxicities and lack of proven advantage in survival upon the increased duration of therapy. Therefore, the first-line therapy with novel agents able to increase the duration of disease stabilization or to improve the response to platinum-based regimens is a recognized medical need in NSCLC. This study shows that acetyl-L-carnitine (ALC) is a sensitizer of platinum compounds in NSCLC tumors carrying wild-type p53. Moreover, the therapeutic advantage of ALC is its antimetastatic activity in a lung carcinoma model. Both effects, likely related to modulation of protein acetylation, may have relevant therapeutic implications in the first line of NSCLC therapy, combined with the excellent in vivo tolerability of ALC and its protective action against cisplatin-induced nephrotoxicity or peripheral neuropathy.

also indicated a significant antimetastatic activity of ALC in the H460/M model, which is characterized by the ability to generate spontaneous metastasis to lung when s.c. xenografted. This antimetastatic efficacy was improved in combination with cisplatin as well as with the HDAC inhibitor ST3595. The increase of p53 response in treated tumors was consistent with its involvement in sensitization to platinum compounds by ALC.

\section{Materials and Methods}

\section{Drugs}

Cisplatin and carboplatin (Teva Pharma Italia S.r.l.) were diluted in saline $(0.15 \mathrm{~mol} / \mathrm{L} \mathrm{NaCl})$. ST3595 (SigmaTau) was dissolved in DMSO/ethanol/PBS (10:5:85). ALC was dissolved in saline. In in vivo studies, all agents were administered in a volume of $10 \mathrm{~mL} / \mathrm{kg}$.

\section{Cell lines and cell sensitivity to drugs}

The human tumor cell systems used in the study included a colon carcinoma (SW620; American Type Culture Collection or ATCC), two NSCLCs (NCI-H460 and H1650 cell lines; ATCC), two prostate carcinoma cell lines (PC3 and LNCaP; ATCC), and a multidrug-resistant ovarian carcinoma cell line (A2780/Dx; European Collection of Animal Cell Cultures). The NSCLC cells and the prostate carcinoma cells were grown in RPMI 1640 (Lonza) supplemented with $10 \%$ fetal bovine serum (FBS, Invitrogen), whereas SW620 cells were maintained in DMEM (Lonza) plus 10\% FBS.

All cells were maintained in a humidified atmosphere with $5 \% \mathrm{CO}_{2}$ at $37^{\circ} \mathrm{C}$. The used cell lines were character- ized by a variable p53 gene status (http://www-p53.iarc.fr): the NCI-H460, H1650, A549, LNCaP, and A2780/Dx cell lines carried a wild-type p53 gene; SW620 and HT-29 cells exhibited a mutant p53 (exon 8, R273H); PC-3 were p53null as a consequence of a deletion at exon 5 . For each cell line, the experiments done for this study were conducted starting from a frozen cell stock. Such cells when thawed were characterized in house, evaluating morphology, the growth curve, and absence of Mycoplasma. The cell sensitivity to drug was measured in vitro by assessing the inhibition of proliferation by the tetrazolium salt (MTT) assay as described (13). Briefly, cells were seeded in 96-wells tissue culture plates in complete medium (10\% FBS) and, 24 hours after seeding, treated for 72 hours, in medium containing $0.1 \%$ FBS, with cisplating or ST3595, in the presence or absence of ALC ( $10 \mathrm{mmol} / \mathrm{L})$. Low concentrations of FBS were used because it contains carnitines. The drug cytotoxic potency was evaluated by the "ALLFIT" computer program and defined as $\mathrm{IC}_{50}$ (drug concentration required for $50 \%$ inhibition of cell survival). The statistical analysis of the effect of drugs alone and in combination with ALC was done by comparing the $\mathrm{IC}_{50}$ values with the F-test using the ALLFIT program. The antiproliferative effects produced by single-drug treatment and by combination treatment were statistically compared by the Mann-Whitney test.

\section{In vivo studies}

Animals. All experiments were carried out at Sigma-Tau using female athymic nude CD-1 mice, ages 8 to 11 weeks (Harlan), except for the tumor model NCI-H460/M (Charles River) carried out at the Istituto Nazionale Tumori. Mice were maintained in laminar flow rooms with constant temperature and humidity. Experimental protocols were approved by the Ethic Committee for Animal Experimentation of Sigma Tau and of the Istituto Nazionale Tumori according to the United Kingdom Coordinating Committee on Cancer Research Guidelines (14).

Tumor models and evaluation of antitumor activities. The following human tumor xenografts were used for antitumor activity studies: the NSCLC H460, A549, H1650, and the colon carcinoma SW620. Exponentially growing tumor cells $\left(3 \times 10^{6} /\right.$ mouse $)$ were s.c. inoculated in the right flank of nude mice. Groups of at least six mice were used to assess antitumor activity. Drug treatments were started 3 days after tumor injection. Tumor growth was followed by measurements of tumor diameters with a Vernier caliper. Tumor volume (TV) was calculated using the formula: TV $\left(\mathrm{mm}^{3}\right)=\left(d^{2} \times D\right) / 2$, in which $d$ and $D$ are the shortest and the longest diameter, respectively. The efficacy of the drug treatment was assessed as:

(a) TV inhibition percentage (TVI\%) in treated versus control mice, calculated as: TVI\% $=100-($ mean TV treated/mean TV control $\times 100$ ).

(b) $\log _{10}$ cell kill $(L C K)$ calculated by the formula: $L C K=(T-C) / 3.32 \times D T$, in which $T$ and $C$ are the mean times (days) required for treated $(\mathrm{T})$ and 
control (C) tumors, respectively, to reach an established $T V$, and $D T$ is the doubling time of control tumors.

When tumors reached a volume of 0.5 to $1 \mathrm{~cm}^{3}$, mice were sacrificed by cervical dislocation. To examine the possible toxicity of treatment, body weight was recorded throughout the study. Student's $t$ test two tailed or Mann-Whitney test were used for statistical analysis of tumor volume.

Evaluation of antimetastatic activity. The H460/M nonsmall cell lung tumor cell line was adapted to grow as ascites in nude mice and maintained in vivo by i.p. passages ( $5 \times 10^{6}$ cells/mouse in $0.5 \mathrm{~mL}$ of PBS). Briefly, cells were collected from the donor mice $\sim 7$ days after inoculum, and after washing, cell number and viability were determined by the trypan blue exclusion test. Cell suspension $\left(5 \times 10^{6}\right.$ cells in $0.25 \mathrm{~mL}$ of PBS) was injected s.c. to achieve spontaneous lung metastases (15). Treatment started at day 1. ALC was dissolved in saline and delivered by mouth, by gavage, at the dose of $200 \mathrm{mg} / \mathrm{kg}$ daily for 4 weeks. Cisplatin was delivered i.v. at the dose of $5 \mathrm{mg} / \mathrm{kg}$ weekly for four times. In mice treated with the combination, ALC was delivered $\sim 1$ hour after cisplatin. For ethical reasons, animals were not allowed to die. Thus, they were inspected daily for any sign of suffering and weighed twice weekly. For the evaluation of spontaneous metastases, mice were sacrificed by cervical dislocation, and their lungs were removed and weighed. Lung lobes were spliced between two glass slides, and the metastatic nodules were macroscopically counted against a bright light. Reading of metastases was done by two independent observers, unaware of the experimental group, with an interobserver reproducibility of $>95 \%$. The metastatic nature of these areas was confirmed by histologic analysis.

In vivo evaluation of apoptosis and DNA damage. For histologic and morphometrical analysis, tumors were placed in $10 \%$ buffered formalin or zinc fixative for 24 hours, dehydrated, and embedded in paraffin. Apoptotic cellular DNA fragmentation was quantified as positive nuclei/ $\mathrm{mm}^{2}$ on formalin-fixed, paraffin-embedded tumor tissues by terminal deoxynucleotidyl transferase-mediated nick end labeling (TUNEL) staining, using In Situ Cell Death Detection kit (Roche). For immunohistochemistry 4- $\mu$ mthick sections were baked overnight at $60^{\circ} \mathrm{C}$, deparaffinized in xylene twice for 10 minutes each, and rehydrated in graded concentrations of ethanol. Serial sections were incubated with rat anti- $\gamma$-H2AX (Upstate; $1: 150$ ), using 3,3'-diaminobenzidine as chromogen and hematoxylin counterstaining. Positive and negative controls were included with each batch. Anti- $\gamma$-H2AX and TUNEL-positive nuclei per millimeter squared were evaluated at $\times 400$ magnification. All measurements were done by two researchers in at least 10 randomly selected fields for each case, with an interobserver variability of $<5 \%$.

Quantitative real-time reverse transcription-PCR. Total RNA was isolated from the H460 tumor xenografts by using the Trizol reagent (Invitrogen). Approximately $1 \mu \mathrm{g}$ of total
RNA was used for reverse transcription by using the ThermoScript RT-PCR System (Invitrogen), according to the manufacturer's instructions. Quantitative PCR was done in 96-well plates by using the ABI PRISM 7700 Sequence Detection System instrument and software (Applied Biosystems). Depending on target genes, real-time quantitative PCR analyses were carried out by using either the Taqman probe assay or the SYBR Green I assay. In the first case, amplification mixes $(20 \mu \mathrm{L})$ contained $1 \times$ Taqman Universal PCR Master Mix (Applied Biosystems), $0.3 \mu \mathrm{mol} / \mathrm{L}$ of each primer, and $0.2 \mu \mathrm{mol} / \mathrm{L}$ of the specific Taqman probe. The cycling conditions comprised a 600second denaturation step at $95^{\circ} \mathrm{C}$, followed by 40 cycles of denaturation at $95^{\circ} \mathrm{C}$ for 15 seconds, and annealing/ extension at $60^{\circ} \mathrm{C}$ for 60 seconds. The oligonucleotides used as specific primers and the fluorogenic Taqman probes used for the target gene were designed, using the manufacturer's software and the sequences available in Genbank, to overlap a splice junction, thereby avoiding a potential amplification of contaminating genomic DNA. The sequences of the oligonucleotide primers and Taqman probes used for $p 53$ were as follows: $5^{\prime}-$ TCACCCTTCAGATCCGTG-3' (forward primer), 5' TCCAAGGCCTCATTCAGCTC-3' (reverse primer), and FAM-CGTGAGCGCTTCGAGATGTTCCG-TAMRA (Taqman probe). For $\beta$-actin, Taqman $\beta$-actin detection reagents (Applied Biosystems) were used. A six-point serial standard curve was generated for the target gene. All expression levels were finally normalized to $\beta$-actin levels to correct for sample differences in RNA concentrations. In the quantitative reverse transcription-PCR analyses done by the SYBR Green assay, the final reaction mixture $(20 \mu \mathrm{L})$ contained $1 \times$ QuantiTect SYBR PCR kit (QIAGEN) and 0.2 to $0.3 \mu \mathrm{mol} / \mathrm{L}$ of each primer. Amplifications began with a 600-second denaturation step at $95^{\circ} \mathrm{C}$, followed by 40 cycles of denaturation at $95^{\circ} \mathrm{C}$ for 15 seconds, annealing at $60^{\circ} \mathrm{C}$ for 20 seconds, and extension at $72^{\circ} \mathrm{C}$ for 10 seconds. The oligonucleotides used as specific primers for each target gene were designed, using the manufacturer's software and the sequences available in Genbank, to overlap a splice junction thereby avoiding a potential amplification of contaminating genomic DNA. The sequences of the oligonucleotide primers were as follows: for $p 21,5^{\prime}$-CCTCCCCAGTTCATTGCACTT-3' (forward primer), 5'-AGACAACTACTCCCAGCCCCAT-3' (reverse primer); for bax, 5'-TGGAGCTGCAGAGGATGATTG-3' (forward primer), 5'-CCAGTTGAAGTTGCCGTCAGA-3' (reverse primer); for Puma, 5'-ATGCCTGCCTCACCTTCATCA-3' (forward primer), 5'-CCAAATGAATGCCAGTGGTCA-3' (reverse primer); for Gadd45- $\alpha$, 5'-ACGGTGATGGCATCTGAATGA-3' (forward primer), 5'-CCCCTTGGCATCAGTTTCTGT-3' (reverse primer); and for $p 53 R 2,5^{\prime}$-TGGACAGCAGAAGAGGTCGACT-3' (forward primer), 5'-CATCACTGGCTGCAAAAAAGG-3' (reverse primer). A six-point serial standard curve was generated for each target gene. All expression levels were finally normalized to cyclophilin A in each well. 
Western blot analysis. For the in vitro experiments, human NCI-H460 NSCLC cells (purchased from ATCC) were grown according to ATCC guidelines. For experiments, cells were trypsinized and seeded at $1 \times 10^{6}$ cells per $100 \mathrm{~mm}$ dish in complete medium (RPMI supplemented with $10 \%$ FBS), and allowed to grow overnight at $37^{\circ} \mathrm{C}$ with $95 \% / 5 \%$ air $/ \mathrm{CO}_{2}$. Cells were treated with 0.9 and $1.6 \mu \mathrm{mol} / \mathrm{L}$ of STI 3595 alone or in combination with $10 \mathrm{mmol} / \mathrm{L}$ ALC for 3 hours in a medium with $0.1 \%$ FBS. After three washings with PBS, cell were collected by scrambling, centrifuged at $1,500 \mathrm{rpm}$ at $4{ }^{\circ} \mathrm{C}$, and processed as described for in vivo tumors.

Total proteins were prepared from the H460 tumor xenografts by homogenization in hot SDS sample buffer [0.125 mol/L Tris-HCl (pH 6.8), 5\% SDS] containing $1 \mathrm{mmol} / \mathrm{L}$ phenylmethylsulfonyl fluoride, $10 \mu \mathrm{g} / \mathrm{mL}$ pepstatin, $12.5 \mu \mathrm{g} / \mathrm{mL}$ leupeptin, $10 \mu \mathrm{g} / \mathrm{mL}$ aprotinin, $1 \mathrm{mmol} / \mathrm{L}$ sodium orthovanadate, and $1 \mathrm{mmol} / \mathrm{L}$ sodium molybdate (16). Equal amounts of lysates (usually corresponding to $20 \mu \mathrm{g}$ of total protein) were separated under reducing conditions on SDS-PAGE and then transferred to nitrocellulose filters. After staining with Ponceau $S$ (Sigma) to control protein loading and transfer, filters were incubated with primary specific antibodies at $4{ }^{\circ} \mathrm{C}$ overnight. The primary antibodies used were as follows: anti-p53 (DO-7; DAKO Italia S.p.A.), anti-acetyl-p53 (Lys 373; Upstate Biotechnology), anti-acetyl-p53 (Lys 382; Cell Signaling Technology), anti-p21 (C-19; Santa Cruz Biotechnology), and anti-actin (Sigma Aldrich Italia S.r.l.). Immunoreactive bands were revealed by horseradish peroxidase-conjugated secondary antibodies using enhanced chemiluminescence detection systems (ECL Plus, GE Healthcare S.r.l.) or SuperSignal West Femto Reagent (Pierce). To quantify signals on immunoblots, the developed films were scanned and band densities were analyzed with a specific Image software (STORM 860; Molecular Dynamics). Protein loading equivalence was corrected in relation to the expression of actin.

\section{Results}

\section{Cellular pharmacology studies}

Cell sensitivity to cisplatin alone or in combination with ALC was determined in different tumor cell lines (H460, H1650, A549, LNCaP, and A2780/Dx), characterized by wild-type p53, following 72 hours of exposure to the drug alone or to concomitant combination. ALC was not toxic in a wide range of concentrations (up to $10 \mathrm{mmol} / \mathrm{L}$ ). As shown in Table 1, ALC was effective in sensitizing all the cell lines to cisplatin, as documented by a substantial decrease of $\mathrm{IC}_{50}$ values in the combination. Interestingly, ALC did not modulate cell sensitivity to cisplatin of PC-3 or SW620 and HT-29 cells, in which p53 is null or mutated, respectively.

\section{Antitumor activity studies}

The H460 cells were grown as tumor xenografts in nude mice to compare the efficacy of cisplatin and its combina- tion with ALC. ALC (200 mg/kg) administered by oral route was well tolerated without manifestations of side effects. The treatment with single agent (cisplatin or ALC) produced a partial tumor growth inhibition (no more than 40\%; Table 2). In contrast, the combination of ALC and cisplatin resulted in a significant tumor growth inhibition (79\% ALC versus $40 \%$ cisplatin). In the same tumor model, ALC enhanced the tumor response to carboplatin (TVI\%, 48\% versus 79\%, in the group treated with carboplatin alone versus the group treated with the combination). The efficacy of the cisplatin/ALC combination was examined in two additional NSCLC models carrying wild-type p53 (Table 2). Again, each single agent produced a marginal effect $(\leq 50 \%)$, whereas the combination produced a significant tumor growth inhibition in both lung carcinoma models. In contrast, ALC was not able to enhance the efficacy of cisplatin in the treatment of the SW620 colon carcinoma, a p53-mutant tumor model.

\section{Apoptosis induction and $\mathrm{H} 2 \mathrm{AX}$ phosphorylation in vivo}

Tumor apoptosis analyzed by TUNEL assay in H460 tumor model showed that the combined ALC-cisplatin treatment led to an appreciable increase of TUNEL-positive cells $(P<0.05)$, in particular of tumor cells adjacent to necrosis areas (Fig. 1). Moreover, ALC-cisplatin combination slightly but significantly $(P<0.05)$ increased the percentage of $\gamma$-H2AX-positive cells as well as the immunostaining intensity of the positive cells compared with cisplatin alone, suggesting that combined therapy potentiated DNA damage. Instead, ALC treatment alone was ineffective when compared with vehicle (Fig. 1).

Table 1. Cell sensitivity to cisplatin alone or in combination with ALC

\begin{tabular}{|c|c|c|c|c|}
\hline \multirow[t]{2}{*}{ Cell lines } & \multirow[t]{2}{*}{$\begin{array}{l}\text { P53 } \\
\text { status }\end{array}$} & Cisplatin & $\begin{array}{l}\text { Cisplatin } \\
\text { plus ALC } \\
\end{array}$ & \multirow[t]{2}{*}{$P$} \\
\hline & & \multicolumn{2}{|c|}{$\mathrm{IC}_{50} \pm \mathrm{SD}(\mu \mathrm{mol} / \mathrm{L})$} & \\
\hline $\mathrm{NCl}-\mathrm{H} 460$ & Wt & $0.40 \pm 0.04$ & $0.13 \pm 0.02$ & 0.001 \\
\hline $\mathrm{NCl}-\mathrm{H} 1650$ & $\mathrm{Wt}$ & $1.5 \pm 0.1$ & $0.31 \pm 0.06$ & $<0.0001$ \\
\hline A549 & Wt & $1 \pm 0.1$ & $0.5 \pm 0.05$ & 0.04 \\
\hline A2780/Dx & Wt & $0.94 \pm 0.05$ & $0.42 \pm 0.03$ & 0.0001 \\
\hline LNCaP & Wt & $15.3 \pm 2.2$ & $6.4 \pm 1.3$ & 0.01 \\
\hline PC-3 & Null & $4.63 \pm 0.33$ & $4.63 \pm 0.23$ & 1.0 \\
\hline SW620 & Mutant & $17.0 \pm 1.9$ & $16.7 \pm 2.1$ & 0.92 \\
\hline HT-29 & Mutant & $9.3 \pm 1.5$ & $9.6 \pm 2.7$ & 0.92 \\
\hline
\end{tabular}

NOTE: Tumor cells were cultured for $24 \mathrm{~h}$ in complete medium (10\% FBS) and then treated for $72 \mathrm{~h}$ at different concentration of cisplatin in the absence or presence of $10 \mathrm{mmol} / \mathrm{L}$ ALC in medium with $0.1 \%$ FBS. $P$ value was calculated by F-test (ALLFIT). 
Table 2. Antitumor activity of cisplatin or carboplatin delivered i.p. (every 4 days for 3 times) in combination with ALC given by mouth ( $200 \mathrm{mg} / \mathrm{kg}$ daily for $4 \mathrm{wk}$ ) against different tumor xenograft models

\begin{tabular}{|c|c|c|c|c|c|c|}
\hline Tumor & DT $(d)^{*}$ & Drug treatment & Dose (mg/kg) & TVI $\%^{\dagger}$ & $\operatorname{LCK}\left(0.20-1 \mathrm{~cm}^{3}\right)^{\ddagger}$ & BWL \%§ \\
\hline \multirow[t]{5}{*}{$\mathrm{NCl}-\mathrm{H} 460 \mathrm{NSCLC}$} & 3.1 & ALC & 200 & 20 & 0.3 & 0 \\
\hline & & CisPt & 4 & 41 & 0.6 & 8 \\
\hline & & CisPt + ALC & $200+4$ & $79^{\| / 1}$ & 2.5 & 10 \\
\hline & & CarboPt. & 40 & 48 & 0.6 & 3 \\
\hline & & CarboPt + ALC & $200+40$ & $79^{\star \star}$ & 1.5 & 4 \\
\hline \multirow[t]{3}{*}{ A549 NSCLC } & 8.0 & ALC & 200 & 27 & 0.3 & 0 \\
\hline & & CisPt & 4 & 49 & 0.5 & 8 \\
\hline & & CisPt + ALC & $200+4$ & $65^{\dagger t}$ & 0.7 & 13 \\
\hline \multirow[t]{3}{*}{ NCl-H1650 NSCLC } & 12.0 & ALC & 200 & 19 & 0.02 & 1 \\
\hline & & CisPt & 4 & 23 & 0.15 & 10 \\
\hline & & CisPt + ALC & $200+4$ & $62^{\ddagger \ddagger}$ & 0.40 & 13 \\
\hline \multirow[t]{3}{*}{ SW620 Colon ca. } & 6.2 & ALC & 200 & 28 & 0.4 & 0 \\
\hline & & CisPt & 4 & 34 & 0.5 & 11 \\
\hline & & $\mathrm{CisP}+\mathrm{ALC}$ & $200+4$ & 43 & 0.6 & 10 \\
\hline
\end{tabular}

NOTE: $n=8-12$ mice/group. $P$ value was evaluated by Mann-Whitney test.

Abbreviations: CisPt, cisplatin; CarboPt, carboplatin.

*Doubling time.

${ }^{\dagger}$ Tumor volume inhibition.

${ }^{\ddagger} \log _{10}$ cell kill.

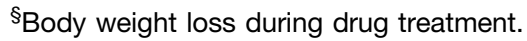

" $P<0.001$ versus cisplatin-treated group.

"One mouse had complete response

${ }^{\star *} P<0.05$ versus carboplatin-treated group.

${ }^{\dagger \dagger} P<0.05$ versus cisplatin-treated group.

${ }^{\ddagger \ddagger} P<0.01$ versus cisplatin-treated group.

\section{Antimetastatic effect of the combination of cisplatin and ALC}

The efficacy of the combination of cisplatin and ALC was investigated in the treatment of a subline of the H460 tumor (H460/M), selected for its metastatic potential (i.e., ability to generate lung metastasis following s.c. inoculation of tumor cells; Table 3; ref. 15). The H460/M tumor subline was poorly responsive to cisplatin because the drug alone produced only 33\% reduction of tumor growth (evaluated $10 \mathrm{~d}$ after the end of treatments) and resulted completely inefficient in inhibiting the metastatic process. The effect on the growth of the primary tumor was improved in animals treated with the combination, resulting in a significant tumor growth and lung metastasis inhibition. Surprisingly, in spite of the limited effect on primary tumor growth (only $28 \%$ of TVI), ALC itself exhibited a significant antimetastatic activity and its therapeutic effect was enhanced in the combination with cisplatin.

\section{Antimetastatic efficacy of the ALC combination with a HDAC inhibitor}

Based on the observation that ALC provides acetyl groups for protein acetylation $(5,6)$, it is conceivable that
ALC may have a cooperative effect with HDAC inhibitors. It is well known that the acetylation of critical proteins mediated by HDAC6 is involved in the regulation of the malignant behavior of tumor cells, particularly in the metastatic process $(17,18)$. Based on this rationale, we explored the ability of ALC to potentiate the antimetastatic effect of a novel HDAC inhibitor, ST3595, which is a broad-spectrum inhibitor with a preferential activity toward HDAC6 (19). Both agents, delivered daily p.o., significantly reduced the number of lung metastases (Table 3 ). The therapeutic efficacy of the two agents was increased when administered in combination. Indeed, the formation of lung metastases was inhibited up to $83 \%$ versus control mice $(P<0.005)$.

Biochemical analysis of p53 and p53-related proteins

The transcription factor p53 has been implicated as a determinant of the efficacy of antitumor DNA-damaging agents, in particular of platinum compounds $(9,11)$. P53 is a substrate for both histone acetylase (e.g., p300) and HDAC in response to DNA damage $(7,8)$. Lysine acetylation of p53 enhances its DNA-binding activity and promote protein stability (8). Based on the putative role of ALC as a donor of acetyl groups, we investigated the in vivo 
modulation of the p53 pathway in response to drug treatment. Biochemical analysis, done in the H460 tumor samples 24 hours after cisplatin treatment, revealed a stabilization of p53 as indicated by increased levels of the protein in the absence of modulation of mRNA levels (Fig. 2A and B). The protein accumulation was substantially increased in tumors treated with the ALC/cisplatin combination, in spite of a negligible effect of ALC alone. Again, although the increase of p53 acetylation at Lys373 after treatment with single agent (ALC or cisplatin) was barely detectable, the combination substantially enhanced Lys373 acetylation (Fig. 2E). Although the modulation of acetylation of Lys382 was less marked, the increase produced by the combination was still evident. Accordingly, several genes including $p 21$ (Fig. 2C and D) and GADD45, $\alpha$ PUMA, Bax, and P53R2 (Fig. 2F), known to be regulated by p53 in response to DNA damage, were induced by cisplatin and more markedly by the combined treatment. Taken together, these results suggest that the ALC positively modulates the cell death proapoptotic pathway induced by cisplatin.

\section{In vitro studies on interaction of ALC with HDAC inhibitors}

In in vitro experiments designed to better clarify the molecular interaction between ALC and ST3595, in NCIH460 (Fig. 3A), a significant enhancement of the antiproliferative activity of ST3595 in combination with ALC was observed at all tested concentrations (Fig. 3A). The sensitization by ALC is more evident at low concentration of ST3595. In the same cell line, the combination of ALC with two concentrations of ST3595 $(0.9$ and $1.6 \mu \mathrm{mol} / \mathrm{L}, \mathrm{i}$. e., $\mathrm{IC}_{50}$ and $\mathrm{IC}_{80}$, respectively) resulted in an enhanced dose-dependent activation of p53, as shown by protein

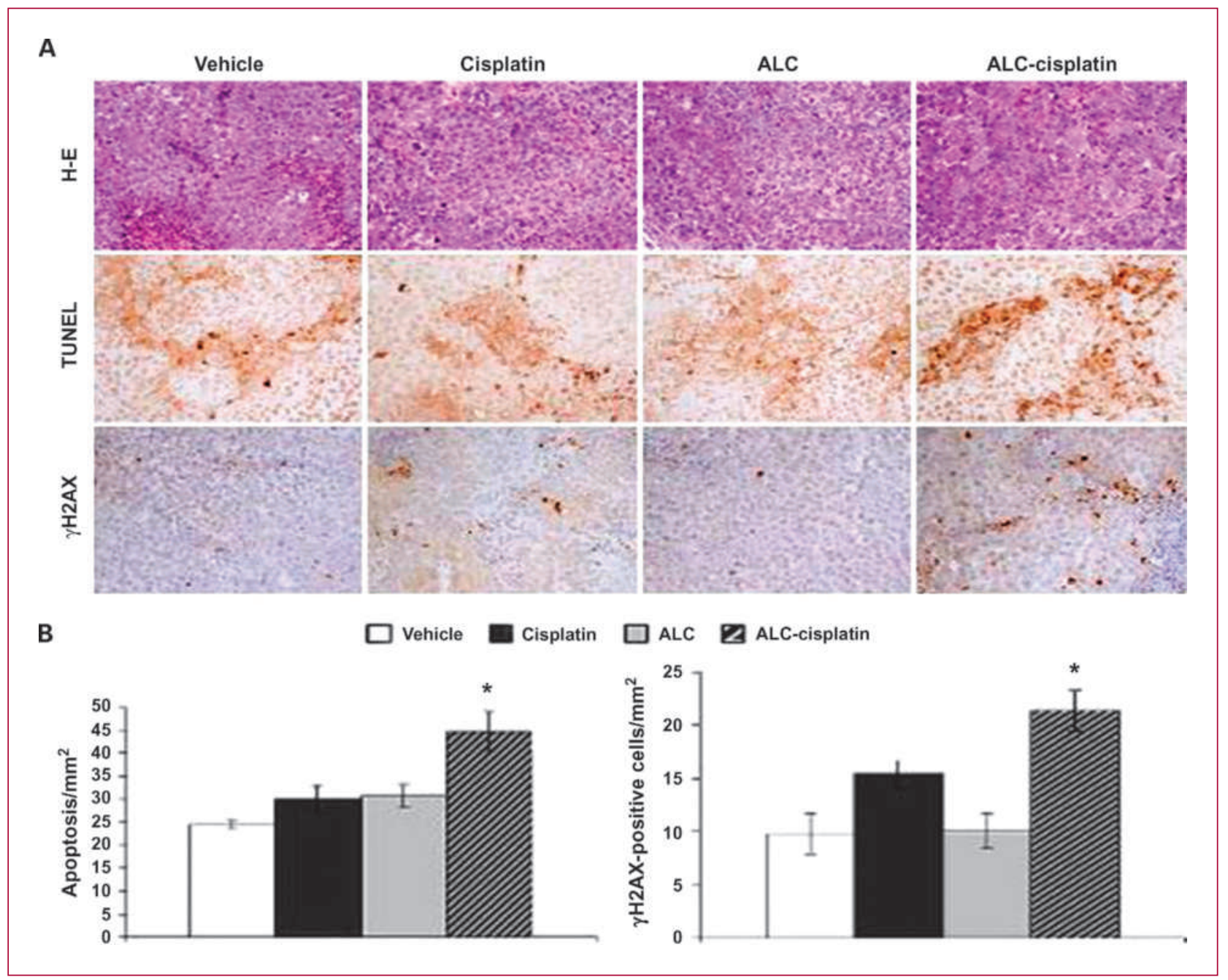

Fig. 1. Apoptosis and $\mathrm{yH} 2 \mathrm{AX}$ induction by cisplatin alone or its combination with $\mathrm{ALC}$ in $\mathrm{H} 460$ tumor xenografts. Serial paraffin sections of $\mathrm{H} 460$ tumor xenografts, grown in CD-1 male nude mice obtained from nontreated (vehicle), control, cisplatin-, ALC-, or ALC cisplatin-treated mice. Top to the bottom, representative images of H\&E, TUNEL, and immunohistochemical staining for $\mathrm{YH} 2 \mathrm{AX}$. Scale bars, $50 \mu \mathrm{m}$ at original magnification $\times 200$. $\mathrm{B}$, semiquantitative evaluation of TUNEL and $\mathrm{yH} 2 \mathrm{AX}$-positive cells on tumor xenografts sections; Student's test: *, $P<0.05$. 
Table 3. Effects of the combination of cisplatin delivered i.v. (5 mg/kg weekly for four times) or ST3595 and ALC given by mouth ( $200 \mathrm{mg} / \mathrm{kg}$ daily for $4 \mathrm{wk})$ on the growth of s.c. tumor and spontaneous lung metastases of the NSCLC H460/M xenograft

\begin{tabular}{|c|c|c|c|c|c|c|}
\hline \multirow[t]{2}{*}{ Drug (mg/kg) } & \multirow[t]{2}{*}{ Dose } & \multirow[t]{2}{*}{ TVI\%* } & \multirow[t]{2}{*}{ BWL $\%^{\dagger}$} & \multirow[t]{2}{*}{ Tox $^{\ddagger}$} & \multicolumn{2}{|c|}{ No. of metastases (day +53 ) } \\
\hline & & & & & Median (range) & Inhibition \% \\
\hline Controls & - & - & 2 & - & $14(6-28)$ & - \\
\hline cisPt & 5 & 33 & 14 & $2 / 6(53,53)$ & $15(2-30)$ & 0 \\
\hline ALC & 200 & 28 & 1 & $0 / 6$ & $7(2-15)$ & $50^{\S}$ \\
\hline CisPt + ALC & $5+200$ & $50^{\|}$ & 16 & $1 / 5(38)$ & $4(0-10)$ & $68^{\S}$ \\
\hline Controls & - & - & 1 & $2 / 17^{\uparrow}$ & $20.4(4-70)$ & - \\
\hline ST3595 & 100 & 29 & 0 & $0 / 12$ & $7.3(2-16)$ & $64^{\S}$ \\
\hline ALC & 200 & 30 & 1 & $0 / 12$ & $10.0(1-42)$ & $51^{\S}$ \\
\hline ST3595 + ALC & $100+200$ & $44^{\|}$ & 0 & $0 / 6$ & $3.5(1-9)$ & $83^{\star \star}$ \\
\hline
\end{tabular}

*Tumor volume inhibition percent in treated over control mice, calculated $10 \mathrm{~d}$ after the end of treatments.

${ }^{\dagger}$ Body weight loss during drug treatment.

${ }^{\ddagger}$ Number of toxic deaths/total number of mice.

${ }^{\S} P<0.05$ versus controls (Mann-Whitney test)

" $P<0.05$ versus control tumors, Student's test.

"Two of 17 deaths for disease.

${ }^{\star \star} P<0.005$ versus controls (Mann-Whitney test).

levels (Fig. 3B). Under the same conditions, (3-h exposure), p53 acetylation was increased in the combination. Again, in keeping with the antiproliferative effect, the enhancement of acetylation produced by combination was more evident at the lower ST3595 concentration.

\section{Effect of ALC treatment on carnitine levels in mice treated with cisplatin or cisplatin plus ALC}

Several clinical studies have evidenced that the treatment with cytotoxic agents may lead to plasma carnitine pool depletion in patients $(20,21)$. To assess whether depletion of carnitine after cisplatin treatment was evident in our experimental model as in patients, plasma levels of ALC and carnitine were examined. In addition, to verify possible changes in cisplatin pharmacokinetics induced by ALC, platinum concentration in tumor and blood was examined at two different time points.

In vivo carnitine levels were measured in the plasma of H460 tumor-bearing mice, 6 and 48 hours following the last administration of cisplatin and ALC. Cisplatin substantially reduced ALC levels (32\% reduction of cisplatin-treated group versus control group), but did not modulate L-carnitine content. ALC by itself was able to increase both L-carnitine and ALC levels, and this enhancement was maintained in the combination. Such a phenomenon was evident at both tested time points (Supplementary Table S1). Analysis of cisplatin levels in blood and tissues from mice treated with cisplatin or ALC plus cisplatin-treated groups revealed no differences in cisplatin content, thus suggesting that ALC did not affect the cisplatin pharmacokinetics (Supplementary Table S2).

\section{Discussion}

Although platinum compounds are components of standard chemotherapy regimens, there is an urgent need for developing strategies to improve their clinical efficacy. In this context, the use of epigenetic approaches, in particular those tailored to modulation of acetylation processes, offers novel opportunities for improving activity of platinum drugs. Because acetylation of critical cellular proteins can be modulated by using acetyl ester of L-carnitine, in the present study, we explored the possibility to improve the effect of platinum compounds using this metabolic modulator, which provides a source of acetyl groups for several cellular processes including gene transcription and activation of apoptosis pathways. Indeed, ALC has been reported to have multiple biological activities related to its central role in energy metabolism mainly regulating the level of acetyl-CoA (1-4).

Several lines of evidence support that ALC plays a role as modulator of cellular stress response and may have a protective function in chemotherapy-induced neurotoxicity $(4,5)$. Our findings document a novel action of ALC. Indeed, here, we provide evidence that ALC was able to enhance the efficacy of cisplatin in human lung carcinoma models relatively resistant to platinum-based therapy, in spite of the presence of a functional wild-type p53. The sensitization of drug carcinoma cells to cisplatin by ALC was also observed in vitro under conditions in which ALC itself did not produced inhibition of cell growth, in spite of relatively high concentrations. The lack of in vitro antiproliferative effects of ALC itself was consistent with 
its excellent in vivo tolerability of protracted daily treatment with $200 \mathrm{mg} / \mathrm{kg}$. However, the in vivo efficacy of ALC was higher than expected on the basis of the low potency observed in vitro. Relevant to this point is the observation that ALC administration produced an increase of plasma levels of L-carnitine and ALC, and counterbalanced the decrease of plasma levels caused by cisplatin treatment (Supplementary Table S3).

The available evidence strongly supports a role for the p53 pathway in the improvement of cisplatin efficacy in combination with ALC. Indeed, ALC was not effective in enhancing cisplatin activity against a p53-defective tumor model (SW620). Thus, ALC may provide a source of acetyl groups for acetylation of proteins (e.g., p53) involved in cellular response to DNA damage. The critical role of dynamic acetylation and deacetylation on cellular functions during stress conditions is supported by the ability of
HDAC inhibitors to confers sensitivity of tumor cells to DNA-damaging agents (22-27).

P53 is well recognized as central mediator of cellular response to DNA damage, (28) and normal p53 function is implicated as a determinant of tumor responsiveness to platinum compounds $(11,12,29)$. Phosphorylation of p53 at various sites (Ser15, Thr18, and Ser20) stimulates the recruitment of histone acetyltransferase p300 that promote COOH-terminal acetylation, thus enhancing its stability and transcriptional activity (7). Moreover, p53 acetylation promotes its activation by reducing the association with its negative regulator MDMI 2 (30).

The results of our study indicated that ALC was able to enhance the p53 activation and the transcriptional activity induced by cisplatin treatment in H460 tumors (Fig. 3). The involvement of the p53 pathway in the sensitization by ALC was also supported by stimulation of
A

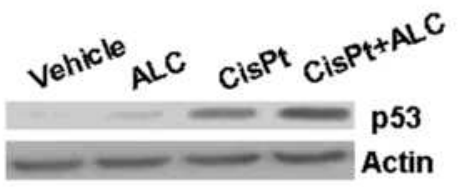

C

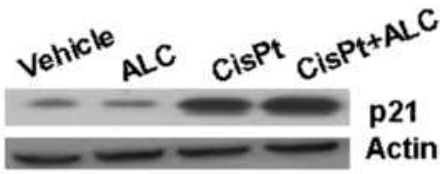

E

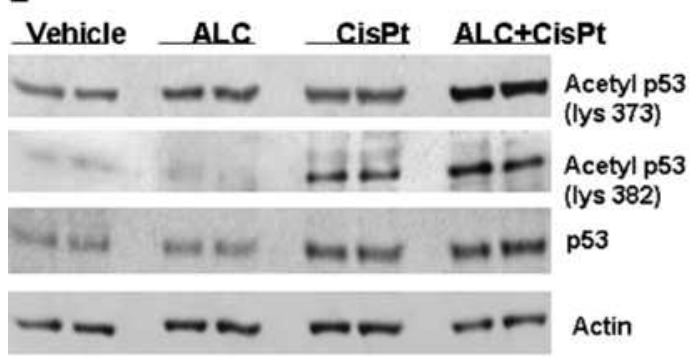

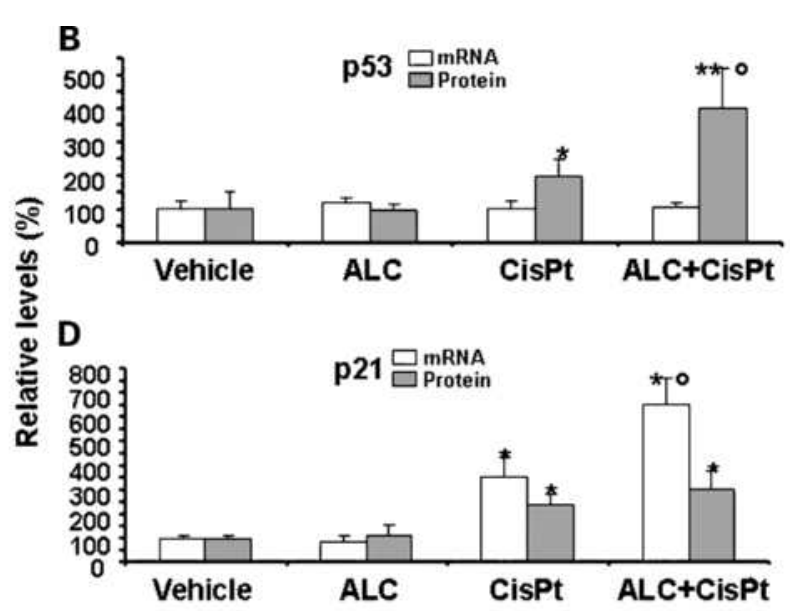

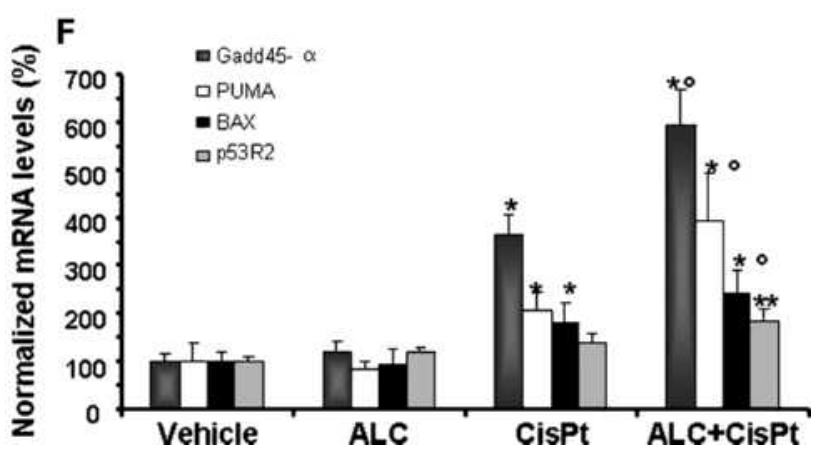

Fig. 2. Analysis of modulation of p53 and p53 target gene expression (protein/mRNA) in NCl-H460 tumor xenografts treated with ALC, cisplatin (CisPt) alone, or in combination. Tumor-bearing mice were treated with cisplatin (4 mg/kg) and/or ALC (200 mg/kg), and tumors were processed $24 \mathrm{~h}$ after the last treatment as described in Materials and Methods. Protein expression were evaluated by Western blot. The signal was quantified by a specific Image Software as described in Materials and Methods. Actin is shown as loading control. The relative mRNA levels were determined in cDNA samples by quantitative real-time PCR. The indicated relative gene expression shows expression levels that were normalized to cyclophilin $A$ ( $p 21$ ) or $\beta$-actin ( $p 53$ ) expression. A to D, P53 (A) and p21 (C) protein expression were evaluated by Western blot. The signal was quantified by a specific Image Software and normalized to actin signal. P53 (B) and p21 (D) relative mRNA levels. E, effects of cisplatin alone or in combination with ALC on acetylation of p53. $\mathrm{F}$, expression levels of p53-related genes. Data are the mean of two independent experiments, five mice per group: Columns, mean; bars, SD. $P$ value was evaluated by Mann-Whitney test; ${ }^{*}, P \leq 0.05$ versus vehicle-treated group; ${ }^{\star \star}, P \leq 0.01 ;{ }^{\circ}, P \leq 0.05$ versus cisplatin-treated group. 


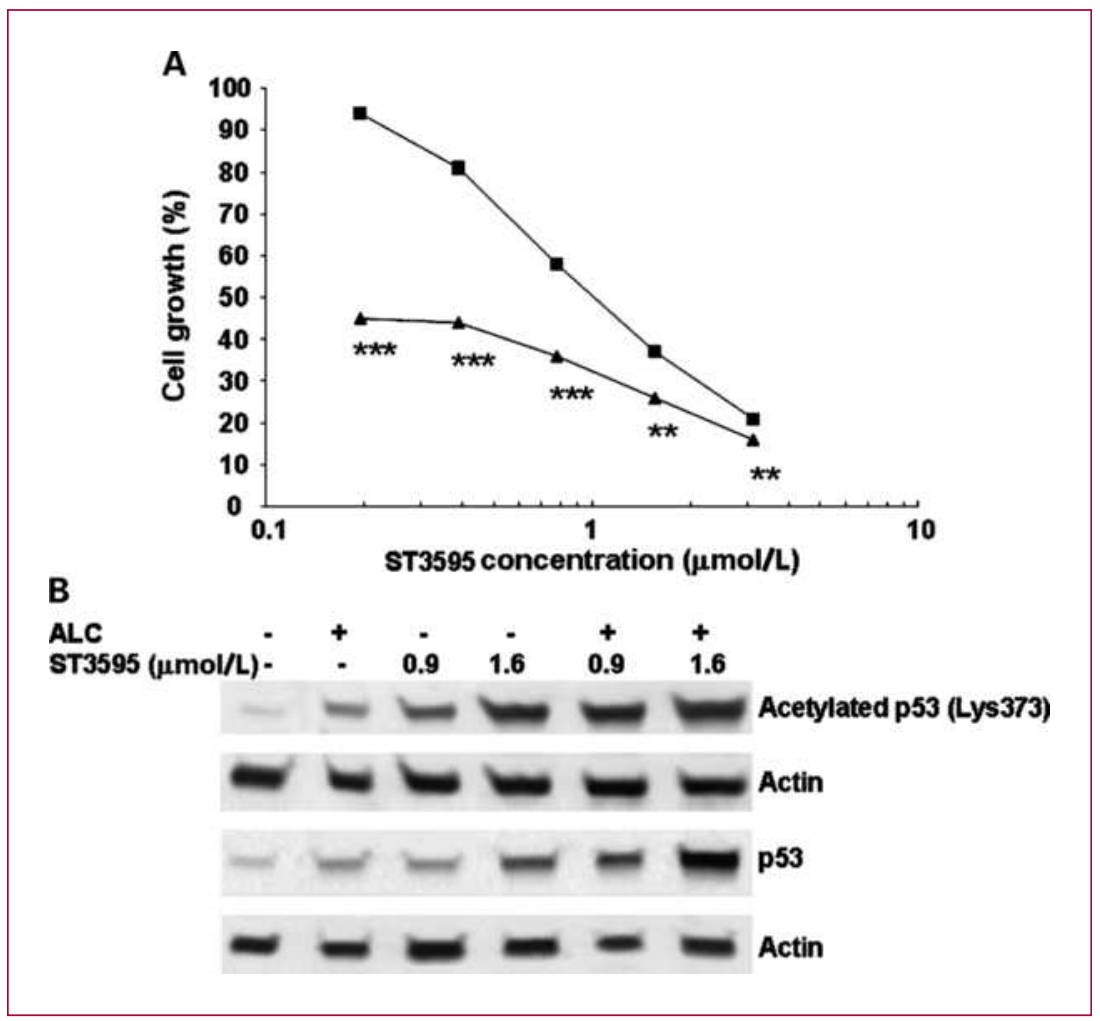

Fig. 3. Cell growth inhibition and p53 modulation after exposure to ST3595 and ALC in $\mathrm{NCl}-\mathrm{H} 460$ cells. A, tumor cells were cultured for $24 \mathrm{~h}$ in $10 \%$ FBS medium and treated for $72 \mathrm{~h}$ with various concentrations of ST3595 in the absence $(\mathbf{\square})$ or presence of $10 \mathrm{mmol} / \mathrm{L}$ ALC $(\mathbf{\Lambda})$ in $0.1 \%$ FBS medium. Cell growth was evaluated by the MTT test, and $\mathrm{IC}_{50}$ and $P$ values (F-test) were calculated by the ALLFIT program. For each concentration, SEM was $\leq 1 \%$. ${ }^{* * *}, P<0.0001 ;{ }^{* \star}, P<0.001$; *, $P<0.005$ of ST3595 plus ALC versus ST3595. $\mathrm{B}, \mathrm{NCl}-\mathrm{H} 460$ cells were treated for $3 \mathrm{~h}$ with ALC, ST3595, or their combination. The treatments were done using $10 \mathrm{mmol} / \mathrm{L} \mathrm{ALC}$ and 0.9 or $1.6 \mu \mathrm{mol} / \mathrm{L}$ ST3595 corresponding to the $\mathrm{IC}_{50}$ and $\mathrm{IC}_{80}$, respectively. P53 and acetylated p53 (acetyl-lys ${ }^{373}$ ) protein expression were evaluated by Western blot. Actin is shown as loading control.

transcription of various genes known to be under the control of p53. In the past, we have shown in rat pheocromocitoma cells that the acetyl group of ALC was used to acetylate histone $\mathrm{H} 4$, increasing the transcriptional activity of nerve growth factor (5). Because acetylcarnitine formed into mitochondria is transported into cytosol by the carnitine/acylcarnitine translocase and then enters the nucleus where it is converted by a nuclear carnitine acetyltransferase to acetyl-CoA, becoming a source of acetyl groups for histone acetylation (6), we assume that p53 acetylation is promoted by this mechanism at a nuclear level in our models.

Moreover, our study does not rule out the possibility of cooperation of multiple effects, taking into account the involvement of ALC in several aspect of cell metabolism. This turns out to be an intriguing interconnection between metabolism, in which ALC plays a key role, and epigenetic phenomena mediated by protein acetylation. This interconnection has been emphasized by Wallace and Fan (31) in a recent review, which addressed how the cellular bioenergetics' systems (glycolysis and mitochondrial phosphorylation) strongly affect protein posttranslational modifications, including phosphorylation and acetylation, resulting in an energetic-epigenetic cooperation.

The present findings also document a novel feature of ALC, i.e., its ability to inhibit the formation of spontaneous lung metastasis. The antimetastatic effect was observed at a dose $(200 \mathrm{mg} / \mathrm{kg})$ that produced only a partial/transient inhibition of primary tumor (Table 3 ).
This observation suggests that ALC exerts a minimal effect on tumor cell proliferation, but it may be able to modify the malignant behavior of invasive tumors. This antimetastatic activity was better exploited in combination with a novel HDAC inhibitor, ST3595. Again, the cooperative effect of ALC and other agents able to modulate protein acetylation supports the notion that ALC plays a role as source of acetyl groups. ST3595 used in the present study is a hydroxamate broad-spectrum HDAC inhibitor that preferentially inhibits HDAC6. The antimetastatic activity of ST3595 was likely related to its profile of inhibition because HDAC6 plays a role in the regulation of intercellular interactions and cellular migration (17). Indeed, ST3595 was very effective in inducing hyperacetylation of tubulin, thus interfering with cell motility. The potentiation of the antimetastatic activity of ST3595 by ALC observed in vivo, together with its enhanced effect on p53 acetylation/stability when combined to ST3595 in vitro, provided additional support to our view of the mechanism of action.

In conclusion, we have shown that ALC had a potential as sensitizer of platinum compounds in NSCLC tumors carrying wild-type p53. Moreover, we have shown for the first time that ALC may have antimetastatic activity in a lung carcinoma model. Both effects, likely related to modulation of protein acetylation, may have obvious therapeutic implications, also taking into account the excellent in vivo tolerability of ALC and its protective action against cisplatin-induced nephrotoxicity (32) or peripheral neuropathy (33). 


\section{Disclosure of Potential Conflicts of Interest}

P. Carminati, C. Cavazza: employees, Sigma-Tau. The other authors disclosed no conflicts of interest.

\section{Acknowledgments}

We thank Laura Zanesi for the editorial assistance and P. Tobia, A. Marconi, and A. Peschechera for their excellent technical assistance.

\section{References}

1. Bremer J. Carnitine metabolism and functions. Physiol Rev 1983;63: 1420-80.

2. Bieber LL. Carnitine. Annu Rev Biochem 1988;57:261-83.

3. Steiber A, Kerner J, Hoppel CL. Carnitine: a nutritional, biosynthetic, and functional perspective. Mol Aspects Med 2004;25:455-73.

4. Calabrese V, Giuffrida Stella AM, Calvani M, Butterfield DA. Acetylcarnitine and cellular stress response: roles in nutritional redox homeostasis and regulation of longevity genes. J Nutr Biochem 2006;17:73-88.

5. Pisano C, Pratesi G, Laccabue D, et al. Paclitaxel and cisplatininduced neurotoxicity: a protective role of acetyl-L-carnitine. Clin Cancer Res 2003;9:5756-67.

6. Madiraju P, Pande SV, Prentki M, Murthy Madiraju SR. Mitochondrial acetylcarnitine provides acetyl groups for nuclear histone. Epigenetics 2009;4:399-403.

7. Lavin MF, Gueven N. The complexity of p53 stabilization and activation. Cell Death Differ 2006;13:941-50.

8. Glozak MA, Sengupta N, Zhang X, Seto E. Acetylation and deacetylation of non-histone proteins. Gene 2005;363:15-23.

9. Lu C, El-Deiry WS. Targeting p53 for enhanced radio- and chemosensitivity. Apoptosis 2009;14:597-606.

10. Beretta GL, Gatti L, Benedetti V, Perego P, Zunino F. Small molecules targeting p53 to improve antitumor therapy. Mini Rev Med Chem 2008;8:856-68.

11. Righetti SC, Della Torre G, Pilotti S, et al. A comparative study of $p 53$ gene mutations, protein accumulation, and response to cisplatinbased chemotherapy in advanced ovarian carcinoma. Cancer Res 1996;56:689-93.

12. Shelling AN. Role of $p 53$ in drug resistance in ovarian cancer. Lancet 1997;349:744-5.

13. Perego $\mathrm{P}$, Romanelli $\mathrm{S}$, Carenini $\mathrm{N}$, et al. Ovarian cancer cisplatinresistant cell lines: multiple changes including collateral sensitivity to taxol. Ann Oncol 1998;9:423-30.

14. Workman $P$, Twentyman $P$, Balkwill F, et al. United Kingdom Coordinating Committee on Cancer Research (UKCCCR) guidelines for the welfare of animals in experimental neoplasia (second edition). Br J Cancer 1998;77:1-10.

15. Cassinelli G, Lanzi C, Petrangolini G, et al. Inhibition of c-Met and prevention of spontaneous metastatic spreading by the 2 -indolinone RPI-1. Mol Cancer Ther 2006;5:2388-97.

16. Gatti $L$, Supino $R$, Perego $P$, et al. Apoptosis and growth arrest induced by platinum compounds in U2-OS cells reflect a specific DNA damage recognition associated with a different p53-mediated response. Cell Death Differ 2002;9:1352-9.

17. Valenzuela-Fernandez A, Cabrero JR, Serrador JM, Sanchez-Madrid F. HDAC6: a key regulator of cytoskeleton, cell migration and cellcell interactions. Cell 2008;18:291-7.

18. Kapoor S. Inhibition of HDAC6-dependent carcinogenesis: emerging, new therapeutic options besides belinostat. Int J Cancer 2009; 124:509.

\section{Grant Support}

Associazione Italiana per la Ricerca sul Cancro, Milan, Italy, by the Ministero della Salute, Rome, Italy and by the European Community (grant CHEMORES).

The costs of publication of this article were defrayed in part by the payment of page charges. This article must therefore be hereby marked advertisement in accordance with 18 U.S.C. Section 1734 solely to indicate this fact.

Received 04/14/2010; revised 06/07/2010; accepted 06/10/2010; published OnlineFirst 06/18/2010.

19. Dallavalle S, Cincinelli R, Nannei R, et al. Design, synthesis, and evaluation of biphenyl-4-yl-acrylohydroxamic acid derivatives as histone deacetylase (HDAC) inhibitors. Eur J Med Chem 2009;44: 1900-12.

20. Hockenberry MJ, Hooke MC, Gregurich M, McCarthy K. Carnitine plasma levels and fatigue in children/adolescents receiving cisplatin, ifosfamide, or doxorubicin. J Pediatr Hematol Oncol 2009;31: 664-9.

21. Haschke M, Vitins $T$, Lüde $S$, et al. Urinary excretion of carnitine as a marker of proximal tubular damage associated with platin-based antineoplastic drugs. Nephrol Dial Transplant 2010;25:426-33.

22. Munshi A, Kurland JF, Nishikawa T, et al. Histone deacetylase inhibitors radiosensitize human melanoma cells by suppressing DNA repair activity. Clin Cancer Res 2005;11:4912-22.

23. Munshi A, Tanaka T, Hobbs ML, Tucker SL, Richon VM, Meyn RE. Vorinostat, a histone deacetylase inhibitor, enhances the response of human tumor cells to ionizing radiation through prolongation of Y-H2AX foci. Mol Cancer Ther 2006;5:1967-74.

24. Kim IA, Shin JH, Kim JH, et al. Histone deacetylase inhibitormediated radiosensitization of human cancer cells: class differences and the potential influence of p53. Clin Cancer Res 2006;12:940-9.

25. Chen $\mathrm{C}-\mathrm{S}$, Wang $\mathrm{Y}-\mathrm{C}$, Yang $\mathrm{H}-\mathrm{C}$, et al. Histone deacetylase inhibitors sensitize prostate cancer cells to agents that produce DNA double-strand breaks by targeting Ku70 acetylation. Cancer Res 2007;67:5318-27.

26. Ozaki K, Kishikawa F, Tanaka M, Sakamoto T, Tanimura S, Kohno M. Histone deacetylase enhance the chemosensitivity of tumor cells with cross-resistance to a wide range of DNA-damaging drugs. Cancer Sci 2008;99:376-84.

27. Geng $L$, Cuneo KC, Fu A, et al. Histone deacetylase (HDAC) inhibitor LBH589 increases duration of $\mathrm{y}-\mathrm{H} 2 \mathrm{AX}$ foci and confines HDAC4 ti cytoplasm in irradiated non-small cell lung cancer. Cancer Res 2006;66:11298-304.

28. Kim E, Giese A, Deppert W. Wild-type p53 in cancer cells: when a guardian turns into a blackguard. Biochem Pharmacol 2009;77: 11-20.

29. Vekris A, Meynard D, Haaz MC, Bayssas M, Bonneti J, Robert J. Molecular determinants of the cytotoxicity of platinum compounds: the contribution of in silico research. Cancer Res 2004;64:356-62.

30. Tang Y, Zhao W, Chen Y, Zhao Y, Gu W. Acetylation is indispensable for p53 activation. Cell 2008;133:612-26.

31. Wallace DC, Fan W. Energetics, epigenetics, mitochondrial genetics. Mitochondrion 2010;10:12-31.

32. Tufekci O, Gunes D, Ozugul C, et al. Evaluation of the effect of acetyl-L-carnitine on experimental cisplatin nephrotoxicity. Chemotherapy 2009;55:451-9.

33. Bianchi G, Vitali G, Caraceni A, et al. Symptomatic and neurophysiological responses of paclitaxel- or cisplatin-induced neuropathy to oral acetyl-L-carnitine. Eur J Cancer 2005;41:1746-50. 


\section{Clinical Cancer Research}

\section{Metabolic Approach to the Enhancement of Antitumor Effect of Chemotherapy: a Key Role of Acetyl-I-Carnitine}

Claudio Pisano, Loredana Vesci, Ferdinando Maria Milazzo, et al.

Clin Cancer Res 2010;16:3944-3953. Published OnlineFirst June 18, 2010. $\begin{array}{ll}\text { Updated version } & \begin{array}{l}\text { Access the most recent version of this article at: } \\ \text { doi:10.1158/1078-0432.CCR-10-0964 }\end{array}\end{array}$

Supplementary Access the most recent supplemental material at:

Material http://clincancerres.aacrjournals.org/content/suppl/2010/08/10/1078-0432.CCR-10-0964.DC1

Cited articles This article cites 33 articles, 9 of which you can access for free at:

http://clincancerres.aacrjournals.org/content/16/15/3944.full\#ref-list-1

E-mail alerts Sign up to receive free email-alerts related to this article or journal.

Reprints and To order reprints of this article or to subscribe to the journal, contact the AACR Publications Subscriptions Department at pubs@aacr.org.

Permissions To request permission to re-use all or part of this article, use this link http://clincancerres.aacrjournals.org/content/16/15/3944.

Click on "Request Permissions" which will take you to the Copyright Clearance Center's (CCC) Rightslink site. 